\title{
What Behaviors Are Important for Successful Weight Maintenance?
}

\author{
Makiko Nakade, ${ }^{1}$ Naomi Aiba, ${ }^{2}$ Akemi Morita, ${ }^{1}$ Motohiko Miyachi, ${ }^{3}$ \\ Satoshi Sasaki, ${ }^{4}$ and Shaw Watanabe ${ }^{1}$ \\ ${ }^{1}$ Nutritional Epidemiology Program, National Institute of Health and Nutrition, 1-23-1 Toyama, Shinjuku-ku, \\ 162-8636 Tokyo, Japan \\ ${ }^{2}$ Department of Nutrition and Life Science, Kanagawa Institute of Technology, 243-0292 Kanagawa, Japan \\ ${ }^{3}$ Health Promotion and Exercise Program, National Institute of Health and Nutrition, Tokyo, Japan \\ ${ }^{4}$ Department of Social and Preventive Epidemiology, School of Public Health, The University of Tokyo, \\ 113-0033 Tokyo, Japan
}

Correspondence should be addressed to Makiko Nakade, makikon@nih.go.jp

Received 14 September 2011; Revised 13 December 2011; Accepted 13 December 2011

Academic Editor: R. Prager

Copyright (C) 2012 Makiko Nakade et al. This is an open access article distributed under the Creative Commons Attribution License, which permits unrestricted use, distribution, and reproduction in any medium, provided the original work is properly cited.

\begin{abstract}
Purpose. To examine behavioral factors related to successful weight maintenance. Methods. Subjects were 90 middle-aged participants who attended a weight loss program and were followed for one year. The subjects were classified into either successful weight maintainers (maintained a weight loss of 5\% or more from their initial weight for one year) (SWM) or unsuccessful weight maintainers (USWM), and weight control practice, stress, obstacles, support, and self-efficacy during the program and followup period were compared. Results. SWM had mean loss of $12 \%$ from their initial weight during the program. They showed a greater improvement in their regularity of eating, walked more, and felt less stress regarding their increased physical activity than the USWM. During the follow-up period, significantly more SWM participants had self-efficacy (for measuring weight, practicing dietary objective, and assessing the practice and keeping records), actually kept records and measured weight more than the USWM participants. In contrast, more USWM participants felt stress about measuring weight. Conclusion. In addition to a substantial initial weight loss due to an increased amount of physical activity, having a higher self-efficacy and consistently keeping records of one's activities, as well as regularly weighing themselves, may be important for successful weight maintenance.
\end{abstract}

\section{Introduction}

Obesity is a leading metabolic disease globally [1]. In Japan, one-third of men aged 30-60 and one-fifth of women over 40 years of age are overweight or obese (body mass index (BMI) $25 \mathrm{~kg} / \mathrm{m}^{2}$ and over) [2]. Although the proportions of overweight and obese people are less than those in Europe and the United States, cardiovascular disease risk in the Japanese population has greatly increased, even in those with BMI less than $30 \mathrm{~kg} / \mathrm{m}^{2}[3,4]$.

Losing weight has favorable effects for overweight/obese people; in particular, sustaining a loss of as little as $5-10 \%$ of initial body weight is associated with significant improvement of obesity-related comorbidities $[5,6]$. Therefore, to date, a large number of weight loss programs that incorporate a combination of dietary, physical activity, and behavior modification approaches have been conducted. Short-term treatment efficacy has dramatically improved over recent decades [7]. However, the difficulty of longterm weight maintenance has remained a serious problem. According to the NIH Technology Assessment Conference Panel, one-third to two-thirds of the lost weight was regained within one year [8]. Moreover, meta-analysis regarding the effect of weight loss programs reported that, as a whole, only $23 \%$ of the lost weight was maintained after $4-5$ years of followup [9]. Therefore, increasing the weight maintenance rate is a crucial issue. 
Against this background, studies focused on individuals who succeeded in maintaining lost weight have been conducted. Previously, comparisons of weight gainers and weight maintainers were primarily conducted; however, inconsistent criteria of weight regain made it difficult to make comparisons across these studies. On the other hand, recently, with evidence that at least $5 \%$ loss of initial body weight is enough to improve obesity-related comorbidities, focus has been placed on maintaining this criterion for one year or longer [10], rather than preventing any regain. Although comparison between successful weight maintainers according to this definition and unsuccessful weight maintainers has been conducted, there have still been only a few studies focused on this topic. Teixeira et al. compared pretreatment variables between successful participants (who maintained 5\% loss or more of their initial weight after a weight loss program) and unsuccessful participants and concluded that pretreatment psychological and behavioral variables such as dieting history, outcome evaluations, exercise self-efficacy, and quality of life were the predictors of successful weight maintenance [11]. However, in this study, there is a possibility that other psychological and behavioral factors during the intervention or follow-up period affected weight maintenance. Wing and Hill found specific behaviors of successful weight loss maintainers among the subjects of the National Weight Control Registry (NWCR) [12]. They shared common behaviors including eating a diet low in fat, frequent self-monitoring of body weight and food intake, and high levels of regular physical activity. However, comparison with unsuccessful weight maintainers was not conducted. Befort et al. compared successful weight maintainers and unsuccessful weight maintainers and reported that more successful weight maintainers ate more fruits/vegetables, did more exercise, kept records, made plans for exercise, and felt fewer barriers than unsuccessful weight maintainers [13]. However, participants' weight was selfreported, response rate of the survey was only $47 \%$ and weight maintenance for less than one year was included in the analysis. In addition, as far as we know, there have been no studies focused on this topic in Japan.

Saku Control Obesity Program (SCOP) is a behavioral approach-based weight loss program developed in Japan. In this study, we followed the participants for one year and conducted a questionnaire survey about weight control behaviors, stress, obstacles, and support from people during the follow-up period and their confidence in continuing weight control behaviors in the future (self-efficacy). We also assessed stress, obstacles, support, self-efficacy, changes in energy intake, the number of steps walked per day, and eating behavior during the weight loss program. The participants were divided into either successful weight maintainers or unsuccessful weight maintainers and the factors that are important for successful weight maintenance were examined.

\section{Materials and Methods}

2.1. Study Subjects and Weight Loss Program. Subjects were the participants of a one-year weight loss program (Saku
Control Obesity Program (SCOP)) held in Nagano prefecture in Japan in 2007. Recruitment was conducted for people aged 40 to 64 and with a body mass index of $28.4 \mathrm{~kg} / \mathrm{m}^{2}$ or more. Exclusion criteria were psychiatric conditions or physical conditions that would preclude full participation in the study. A total of 116 (57 men and 59 women) met the study criteria and participated in the program. Written information including the purpose of the study, assurance of refusal, and security of personal information was provided to each participant and written informed consent was obtained from all participants. The study protocol was approved by the ethics committee of the National Institute of Health and Nutrition.

The program and physical measurement were conducted at a dock center in Nagano prefecture. In the program, the participants received individual counseling sessions about energy restriction and group sessions for exercise at the baseline and at 1, 3, 6, and 9 months. In the individual counseling, several behavioral strategies such as goal setting and self-monitoring were used. The participants found lifestyle habits (diet, dietary habit and physical activities) that needed improvement and set objectives to modify them with the support of trained registered dietitians and exercise instructors. In addition, they were instructed to self-monitor weight daily, diet and implementation of the plans using a self-monitoring sheet. The months between these five face-to-face counseling sessions (i.e., at 2, 4, 5, 7, 8, 10, and 11 months), participants reported their progress for the previous month and their new plans for the following month by mailing the records to the dietitians. The dietitians checked these and sent back comments to each participant. Only 5 participants dropped out during the program. After the program, the participants significantly lost weight from $81.0 \pm 13.5 \mathrm{~kg}$ to $75.6 \pm 12.2 \mathrm{~kg}(P<0.001$ by paired $t$-test, data not shown).

\subsection{Physical Measurement and Questionnaire Survey}

2.2.1. At the Baseline and at the End of the Program. The participants measured height and weight at the dock center. Height was measured with shoes off, and body weight was measured with light clothes in the fasting state in the morning. Body weight was measured by Bioelectrical Impedance Analysis (TB-220, Tanita Co., Japan). BMI was calculated from the body weight $(\mathrm{kg})$ divided by the height ${ }^{2}$ $\left(\mathrm{m}^{2}\right)$ of each subject.

The participants answered a diet history questionnaire (DHQ) [14-16] and a questionnaire about eating behavior [17] at the baseline and at the end of the program. Energy intake was calculated using an ad hoc computer program for DHQ, which was based on the food composition table in Japan. The questionnaire about eating behavior was made by the Japan Society for the Study of Obesity. This included 51 items based on the statements given by the obese participants in a clinical survey. A four-point Likert scale (strongly disagree/disagree/agree/strongly agree) was used in the questionnaire. Based on these items, scores were calculated for the following eight eating behavior categories: (1) irregularity of eating, (2) perception gap about the feelings of fullness 
and hunger, (3) preference for unhealthy foods, (4) eating on unexpected occasions, (5) perception gap about constitution and weight, (6) eating quickly, (7) motivation for eating, and (8) total score. A higher score indicated that the participants had more features characteristic of obese people. Daily step counts were assessed using a uniaxial accelerometer (Suzuken Co., Japan). Each participant wore a uniaxial accelerometer on his or her belt from the time of waking to going to bed for two weeks before the baseline assessment and the assessment at the end of the program [18]. Participants were unable to view the data so that they would not consequently alter their normal routines of physical activity. We used the mean step counts for two weeks in the analysis.

Only at the end of the program, the participants answered a questionnaire about stress, obstacles, and support during weight loss program and confidence to continue weight control behaviors (practicing dietary objectives, increasing physical activity, and self-monitoring for their weight) (See Table 3). They answered all the questions with "Yes" or "No."

2.2.2. At the End of the Followup. The participants were followed for one year after the program without any intervention. They visited the dock center again at the end of the followup and physical measurement (height and weight), assessment of daily step counts for two weeks, and a questionnaire survey were conducted.

In the questionnaire, the participants were asked whether or not they had any weight control strategies that they had learned in the program (setting objectives for diet and physical activity and practice, and self-monitoring for such practice, weight, and diet), whether or not they experienced any stress or obstacles, and also whether they had any support from people, and finally if they had confidence to continue the weight control behaviors in the future (see Table 4). They answered all the questions with "Yes" or "No." A question on the frequency of weight measuring (times/week) was also included in the questionnaire.

2.3. Statistical Analysis. Because among the 111 subjects who completed the program, 21 subjects did not attend follow-up physical measurement, analyses were based on 90 participants (44 men and 46 women). Using the Institute of Medicine (IOM) definition [10], successful weight maintainers (SWM) were defined as those who maintained a weight loss of $5 \%$ or more of their initial weight at one year's followup assessment and the others were defined as unsuccessful weight maintainers (USWMs).

The percentage of men was compared between SWM and USWM by chi-square test. Age, height, weight, and BMI at the baseline and weight and BMI at the end of the program and followup were compared by $t$-test. Mean energy intake, the number of steps walked per day, and the scores for eating behavior at the end of the program between SWM and USWM were compared using analysis of covariance (ANCOVA) adjusting for age, sex, and baseline values. Stress, obstacles, and support during weight loss program and confidence to continue weight control behaviors in the future between SWM and USWM were compared by logistic regression analysis both without any adjustment and after adjusting for age, sex, and baseline weight. Weight control activities, stress, obstacles, and support during the followup period and confidence in the future between SWM and USWM were also compared by logistic regression analysis both without any adjustment and after adjusting for age, sex, and baseline weight. Frequency of measuring weight was compared by ANCOVA adjusting for age, sex, and baseline weight. The number of steps walked per day at the end of the followup between SWM and USWM was compared using ANCOVA adjusting for age, sex, and the value at the end of the program (or value at the baseline).

$P$ values of less than 0.05 were considered significant. All statistical analyses were carried out using SPSS for Windows (version 16.0; SPSS Inc., Japan).

\section{Results}

Among the 90 participants, 36 participants were classified into successful weight maintainers (SWMs) and 54 were classified into unsuccessful weight maintainers (USWMs).

Baseline characteristics and changes in weight and BMI in each SWM and USWM group are shown in Table 1. There were no significant differences in the proportion of men, baseline age, height, weight, and BMI between the groups. At the end of the program and followup, BMI values in the SWM group were significantly lower than those in the USWM group. On average, the SWM group had lost $12.0 \%$ from the baseline weight at the end of the program and still maintained 9.9\% loss from the baseline at the end of the followup. On the other hand, the USWM group had lost $3.1 \%$ weight at the end of the program and maintained only $0.7 \%$ loss at the end of the followup.

\subsection{Comparison between SWM and USWM during the Weight} Loss Program. Comparisons of the changes in energy intake, the number of steps walked per day, and the scores for eating behavior in SWM and USWM are shown in Table 2. The baseline score for perception gap about the feelings of fullness and hunger in USWM was significantly higher than that in SWM ( $P=0.019$ by $t$-test, data not shown), but no significant differences were seen in the other scores, energy intake, or the number of steps walked in a day. At the end of the program, although no significant difference was seen in the energy intake, the SWM participants were found to walk significantly more than the USWM participants after adjusting for age, sex, and baseline values. The score for irregularity of eating in SWM was also lower than that of USWM (namely., SWM had less irregularity in their eating habits) at the end of the program.

Table 3 shows the results of comparisons between SWM and USWM in terms of stress, obstacles, and support during weight loss program and the confidence of continuing weight control behavior in the future. On the whole, fewer SWM participants felt stress and obstacles in regard to carrying out the dietary objectives, increasing physical activity, and regularly weighing themselves than USWM. In addition, more SWM were confident about carrying out such weight control behavior than USWM. Significant differences were 
TABLE 1: Comparison of baseline characteristics and changes in weight and BMI.

\begin{tabular}{|c|c|c|c|}
\hline & $\operatorname{USWM}(n=54)$ & $\operatorname{SWM}(n=36)$ & $P^{\mathrm{c}}$ \\
\hline \multicolumn{4}{|l|}{ Baseline } \\
\hline Men $(\%)$ & $23(42.6)$ & $21(58.3)$ & 0.143 \\
\hline Age (yr) & $54.9 \pm 6.0$ & $54.8 \pm 6.8$ & 0.930 \\
\hline Height $(\mathrm{cm})$ & $161.3 \pm 8.6$ & $163.3 \pm 10.0$ & 0.317 \\
\hline Weight (kg) & $79.1 \pm 11.1$ & $84.7 \pm 17.1$ & 0.064 \\
\hline BMI $\left(\mathrm{kg} / \mathrm{m}^{2}\right)$ & $30.3 \pm 3.0$ & $31.6 \pm 4.8$ & 0.120 \\
\hline \multicolumn{4}{|l|}{ At the end of the program } \\
\hline Weight (kg) & $76.6 \pm 11.0$ & $74.3 \pm 14.6$ & 0.382 \\
\hline BMI $\left(\mathrm{kg} / \mathrm{m}^{2}\right)$ & $29.5 \pm 2.9$ & $27.9 \pm 4.2$ & 0.033 \\
\hline \multicolumn{4}{|l|}{ At the end of the followup } \\
\hline Weight (kg) & $78.6 \pm 11.5$ & $76.0 \pm 14.6$ & 0.356 \\
\hline BMI $\left(\mathrm{kg} / \mathrm{m}^{2}\right)$ & $30.3 \pm 3.1$ & $28.6 \pm 4.1$ & 0.027 \\
\hline Weight change from baseline $(\%)^{\mathrm{a}}$ & $-3.1 \pm 4.3$ & $-12.0 \pm 5.8$ & \\
\hline Weight change from baseline $(\%)^{\mathrm{b}}$ & $-0.7 \pm 3.1$ & $-9.9 \pm 5.2$ & \\
\hline
\end{tabular}

Values are means \pm SD. BMI: body mass index. SWM: successful weight maintainers. USWM: unsuccessful weight maintainers.

${ }^{a}$ Between baseline and after intervention.

${ }^{b}$ Between baseline and followup.

${ }^{\mathrm{c}}$ Proportion of men was compared by chi-square test. Age, height, weight, and BMI were compared by $t$-test.

TABLE 2: Changes in energy intake, the number of steps walked per day, and the scores for eating behavior in successful weight maintainers and unsuccessful weight maintainers.

\begin{tabular}{|c|c|c|c|c|c|c|c|}
\hline & \multicolumn{3}{|c|}{ USWM } & \multicolumn{3}{|c|}{ SWM } & \multirow[b]{2}{*}{$P^{\mathrm{a}}$} \\
\hline & $n$ & Baseline & $\begin{array}{l}\text { At the end of } \\
\text { the program }\end{array}$ & $n$ & Baseline & $\begin{array}{l}\text { At the end of } \\
\text { the program }\end{array}$ & \\
\hline Energy intake (kcal/day) & 53 & $2098 \pm 710$ & $2030 \pm 667$ & 36 & $2388 \pm 799$ & $2247 \pm 683$ & 0.851 \\
\hline Walking steps (steps/day) & 42 & $8395 \pm 3035$ & $9578 \pm 3055$ & 33 & $8559 \pm 3338$ & $11185 \pm 3677$ & 0.028 \\
\hline Total score & 51 & $95.9 \pm 20.1$ & $90.6 \pm 19.2$ & 33 & $96.1 \pm 16.0$ & $86.0 \pm 16.7$ & 0.099 \\
\hline Irregularity of eating & 51 & $15.9 \pm 4.1$ & $15.4 \pm 3.6$ & 33 & $16.1 \pm 4.5$ & $14.3 \pm 3.7$ & 0.033 \\
\hline $\begin{array}{l}\text { Perception gap about the feelings of fullness and } \\
\text { hunger }\end{array}$ & 51 & $10.5 \pm 3.8$ & $9.9 \pm 3.4$ & 33 & $8.9 \pm 2.3$ & $8.2 \pm 2.4$ & 0.150 \\
\hline Preference for unhealthy foods & 51 & $13.4 \pm 4.3$ & $13.0 \pm 3.8$ & 33 & $14.0 \pm 3.9$ & $12.7 \pm 3.9$ & 0.108 \\
\hline Eating on unexpected occasions & 51 & $6.9 \pm 2.9$ & $6.6 \pm 2.8$ & 33 & $6.8 \pm 2.5$ & $6.3 \pm 2.1$ & 0.787 \\
\hline Perception gap about constitution and weight & 51 & $17.4 \pm 3.0$ & $15.9 \pm 3.5$ & 33 & $16.9 \pm 4.1$ & $15.1 \pm 4.6$ & 0.553 \\
\hline Eating quickly & 51 & $11.9 \pm 3.8$ & $10.9 \pm 3.8$ & 33 & $12.4 \pm 3.1$ & $10.2 \pm 2.8$ & 0.178 \\
\hline Motivation for eating & 51 & $20.0 \pm 6.1$ & $18.8 \pm 5.8$ & 33 & $21.0 \pm 4.7$ & $19.2 \pm 5.0$ & 0.499 \\
\hline
\end{tabular}

Values are means \pm SD.

a ANOVA adjusting for age, sex, and baseline value was conducted.

SWM: successful weight maintainers, USWM: unsuccessful weight maintainers.

seen in the items regarding the stress associated with increasing their physical activity (odds ratio (95\% confident interval) after adjusting for age, sex, and baseline weight was $0.36(0.14-0.94))$.

\subsection{Comparison between SWM and USWM during the Fol-} lowup Period. Comparisons of weight control practice, stress, obstacles, and support during the follow-up period and confidence to continue weight control behaviors in the future (self-efficacy) between SWM and USWM are shown in Table 4.

Significantly more SWM participants answered yes to the questions about self-efficacy for practicing dietary objective, measuring weight, and assessing the practice and keeping records than the USWM participants both without adjustment and after adjusting for age, sex, and baseline weight. Odds ratios (95\% confident interval) after adjusting for age, sex, and baseline weight were 5.45 (1.92-15.45), 2.79 
TABLE 3: Comparisons of participants' stress, obstacles and support during weight loss program and confidence to continue weight control behaviors in the future between successful weight maintainers and unsuccessful weight maintainers.

\begin{tabular}{|c|c|c|c|c|}
\hline & $\begin{array}{c}\text { USWM } \\
\text { Total (\%) }\end{array}$ & $\begin{array}{c}\text { SWM } \\
\text { Total (\%) }\end{array}$ & $\begin{array}{c}\text { Crude }^{\mathrm{a}} \\
\text { OR 95\% CI }\end{array}$ & $\begin{array}{l}\text { Adjusted }^{\mathrm{b}} \\
\text { OR 95\% CI }\end{array}$ \\
\hline \multicolumn{5}{|l|}{ (1) Practicing objectives for the diet } \\
\hline Did you feel stress about practicing the dietary objective? (Yes) & $53(52.8)$ & $35(45.7)$ & $0.75(0.32-1.77)$ & $0.62(0.24-1.57)$ \\
\hline Did you have any obstacles to practicing the dietary objective? (Yes) & $54(38.9)$ & $36(30.6)$ & $0.69(0.28-1.69)$ & $0.80(0.31-2.03)$ \\
\hline Did you receive any support from people around you? (Yes) & $54(48.1)$ & $36(61.1)$ & $1.69(0.72-3.99)$ & $1.34(0.53-3.38)$ \\
\hline Are you confident in practicing the dietary objective in the future? (Yes) & $54(72.2)$ & $35(88.6)$ & $2.98(0.90-9.89)$ & $3.41(0.97-12.03)$ \\
\hline \multicolumn{5}{|l|}{ (2) Increasing physical activity and practice } \\
\hline Did you feel stress about increasing physical activity? (Yes) & $54(55.6)$ & $35(28.6)$ & $0.32(0.13-0.79)$ & $0.36(0.14-0.94)$ \\
\hline Did you have any obstacles to increasing physical activity? (Yes) & $54(42.6)$ & $36(27.8)$ & $0.52(0.21-1.28)$ & $0.55(0.21-1.45)$ \\
\hline Did you receive any support from people around you? (Yes) & $54(25.9)$ & $36(36.1)$ & $1.62(0.65-4.02)$ & $1.65(0.60-4.54)$ \\
\hline Are you confident in increasing physical activity in the future? (Yes) & $54(61.1)$ & $36(77.8)$ & $2.23(0.86-5.80)$ & $2.28(0.79-6.54)$ \\
\hline \multicolumn{5}{|l|}{ (3) Self-monitoring for weight } \\
\hline Did you feel stress about measuring your weight? (Yes) & $54(38.9)$ & $36(25.0)$ & $0.52(0.21-1.33)$ & $0.51(0.18-1.44)$ \\
\hline Did you have any obstacles to measuring your weight? (Yes) & $54(29.6)$ & $36(16.7)$ & $0.48(0.17-1.36)$ & $0.47(0.15-1.45)$ \\
\hline Are you confident in measuring your weight in the future? (Yes) & $54(72.2)$ & $36(86.1)$ & $0.42(0.14-1.28)$ & $0.39(0.12-1.31)$ \\
\hline
\end{tabular}

SWM: successful weight maintainers, USWM: unsuccessful weight maintainers. ${ }^{a}$ logistic regression analysis.

${ }^{b}$ logistic regression analysis after adjusting for age, sex, and baseline weight.

(1.06-7.34), and $2.71(1.08-6.81)$, respectively. In addition, significantly more SWM participants answered yes to the questions about measuring weight and keeping records for assessing their practice (odds ratios after adjusting for age, sex, and baseline weight were $5.84(1.11-30.88)$ and 3.26 (1.29-8.22), resp.). The frequency of weighing tended to be higher in SWM than in USWM $(0.83 \pm 0.35$ times/week versus $0.65 \pm 0.41$ times/week, $P=0.052$ by ANCOVA after adjusting for age, sex, and baseline weight (data not shown)).

The SWM participants felt significantly less stress about measuring weight than the USWM participants (odds ratio after adjusting for age, sex, and baseline weight was 0.05 $(0.01-0.55))$. They also felt less stress regarding assessing their practice and keeping records every day (odds ratio without any adjustment was $0.35(0.13-0.96)$ ), but significance was not seen after adjusting for age, sex, and baseline weight. There were no significant differences in the other items such as obstacles, support from people, increasing physical activity, and self-monitoring for diet. The number of steps walked per day at the end of the followup was also not significantly different between the groups after adjusting for age, sex, and the values at the end of the program (8894 \pm 2867 in USWM and $10281 \pm 3202$ in SWM, respectively, $P=$ 0.664 (data not shown)), but the walking steps in SWM were significantly greater than that in USWM after adjusting for age, sex, and baseline values $(P=0.048$ (data not shown)).

\section{Discussion}

In this study, we examined what behavioral factors were different between successful weight maintainers and unsuccessful weight maintainers. In addition to their having been only a few studies examining this topic using the IOM definition, there were some limitations in each previous study. In our study, there are various strengths, such as that the weight was actually measured, follow-up rate was relatively high $(81 \%)$, and successful weight maintainers were compared with unsuccessful weight maintainers.

In our study, the SWM participants showed a substantial weight loss during the weight loss program; they lost mean of $12.0 \%$ from their initial weight. They also showed a greater improvement in their regularity of eating, walked more, and felt less stress associated with increasing their physical activity than the USWM participants. A previous study also reported that successful weight loss participants perceived fewer barriers for exercise [11]. And because the change in energy intake was not significantly different between the groups, whether or not a person can increase his/her physical activity might be an important factor which distinguishes those who demonstrate greater weight loss from those with less weight loss, and this factor may affect subsequent weight maintenance.

During the follow-up period, the SWM participants had higher self-efficacy about weight control behaviors (such as activities to achieve the dietary objective, measuring weight, and assessing activities and keeping records), and actually kept records and measured weight. Our results were consistent with previous studies. For example, a review study that examined psychological factors of weight maintenance and relapse in obesity suggested that higher self-efficacy was one of the important factors that affect weight maintenance [19]. In addition, study of the National Weight Control Registry members showed that frequent self-weighing was related to weight maintenance $[12,13]$. In this study, 
TABLE 4: Comparisons of participants' weight control practice, stress, obstacles and support during follow-up period and confidence in the future between successful weight maintainers and unsuccessful weight maintainers.

\begin{tabular}{|c|c|c|c|c|}
\hline & $\begin{array}{c}\text { USWM } \\
\text { Total }(\%)\end{array}$ & $\begin{array}{c}\text { SWM } \\
\text { Total }(\%)\end{array}$ & $\begin{array}{l}\text { Crude }^{\mathrm{a}} \\
\text { OR95\% CI }\end{array}$ & $\begin{array}{l}\text { Adjusted }^{\mathrm{b}} \\
\text { OR95\% CI }\end{array}$ \\
\hline \multicolumn{5}{|l|}{ (1) Setting objectives for diet and practice } \\
\hline Did you set an dietary objective during the past year? (Yes) & $54(64.8)$ & $36(77.8)$ & $1.90(0.72-4.98)$ & $2.47(0.84-7.25)$ \\
\hline Did you practice the dietary objective? (Yes) & $52(75.0)$ & $35(74.3)$ & $0.96(0.36-2.58)$ & $1.05(0.36-3.07)$ \\
\hline Did you feel stress about practicing the dietary objective? (Yes) & $43(46.5)$ & $31(32.3)$ & $0.55(0.21-1.43)$ & $0.68(0.25-1.87)$ \\
\hline Did you receive any support from people around you? (Yes) & $44(47.7)$ & $31(54.8)$ & $1.33(0.53-3.34)$ & $1.12(0.42-3.03)$ \\
\hline Are you confident in practicing the dietary objective in the future? (Yes) & $53(43.0)$ & $36(80.6)$ & $5.40(2.01-14.51)$ & $5.45(1.92-15.45)$ \\
\hline \multicolumn{5}{|l|}{ (2) Setting objectives for increasing physical activity and practice } \\
\hline $\begin{array}{l}\text { Did you set an objective for increasing physical activity during the past } \\
\text { year? (Yes) }\end{array}$ & $54(53.7)$ & $36(44.4)$ & $0.69(0.30-1.61)$ & $0.63(0.26-1.52)$ \\
\hline Did you feel stress about increasing physical activity? (Yes) & $45(48.9)$ & $34(41.2)$ & $0.73(0.30-1.80)$ & $0.88(0.34-2.32)$ \\
\hline Did you have any obstacles to increasing physical activity? (Yes) & $48(31.3)$ & $34(41.2)$ & $1.54(0.62-3.85)$ & $2.12(0.75-6.00)$ \\
\hline Did you receive any support from people around you? (Yes) & $48(29.2)$ & $34(32.4)$ & $1.16(0.45-3.01)$ & $1.17(0.44-3.14)$ \\
\hline Are you confident in increasing physical activity in the future? (Yes) & $54(63.0)$ & $36(52.8)$ & $0.66(0.28-1.55)$ & $0.56(0.22-1.40)$ \\
\hline \multicolumn{5}{|l|}{ (3) Self-monitoring for weight } \\
\hline Did you measure your weight? (Yes) & $54(79.6)$ & $36(94.4)$ & $4.35(0.90-20.95)$ & $5.84(1.11-30.88)$ \\
\hline Did you feel stress about measuring your weight? (Yes) & $47(27.7)$ & $34(2.9)$ & $0.08(0.01-0.64)$ & $0.05(0.01-0.55)$ \\
\hline Did you have any obstacles to measuring your weight? (Yes) & $47(14.9)$ & $34(17.6)$ & $1.22(0.37-4.04)$ & $0.92(0.24-3.60)$ \\
\hline Are you confident in measuring your weight in the future? (Yes) & $53(52.8)$ & $36(75.0)$ & $2.68(1.06-6.77)$ & $2.79(1.06-7.34)$ \\
\hline \multicolumn{5}{|l|}{ (4) Self-monitoring for practice } \\
\hline Did you keep records for assessing your practice every day? (Yes) & $54(24.1)$ & $36(52.8)$ & $3.52(1.43-8.71)$ & $3.26(1.29-8.22)$ \\
\hline $\begin{array}{l}\text { Did you feel stress about assessing your practice and keeping records } \\
\text { every day? (Yes) }\end{array}$ & $42(73.8)$ & $30(50.0)$ & $0.35(0.13-0.96)$ & $0.37(0.13-1.04)$ \\
\hline $\begin{array}{l}\text { Did you have any obstacles to assess your practice and keep records } \\
\text { every day? (Yes) }\end{array}$ & $43(32.6)$ & $32(28.1)$ & $0.81(0.30-2.20)$ & $0.74(0.25-2.14)$ \\
\hline $\begin{array}{l}\text { Are you confident in assessing your practice and keeping records every } \\
\text { day in the future? (Yes) }\end{array}$ & $53(32.1)$ & $36(58.3)$ & $2.96(1.23-7.14)$ & $2.71(1.08-6.81)$ \\
\hline \multicolumn{5}{|l|}{ (5) Self-monitoring for diet } \\
\hline Did you keep records for eating at least once a week? (Yes) & $54(22.2)$ & $36(36.1)$ & $1.98(0.78-5.04)$ & $2.07(0.78-5.51)$ \\
\hline Did you have any obstacles to keep records for eating? (Yes) & $47(40.4)$ & $34(38.2)$ & $0.91(0.37-2.25)$ & $0.95(0.36-2.48)$ \\
\hline Are you confident in keeping records for eating in the future? (Yes) & $53(28.3)$ & $36(33.3)$ & $1.27(0.51-3.16)$ & $1.40(0.52-3.74)$ \\
\hline
\end{tabular}

SWM: Successful weight maintainers, USWM: Unsuccessful weight maintainers. ${ }^{a}$ Logistic regression analysis.

${ }^{\mathrm{b}}$ Logistic regression analysis after adjusting for age, sex and baseline weight.

more SWM participants measured their body weight, and weighing frequency tended to be greater than that in the USWM participants. The participants might have been able to identify weight gain at an early stage by self-monitoring of weight and could control it. Keeping records was also identified in a previous study [13]. Assessing practice and keeping records may be related to increased motivation. If the participants consistently undertook activities to meet the objective and kept records, a sense of achievement could develop, which is a great motivator of weight control practice and may contribute to weight maintenance.

Higher physical activity was often reported to be a factor related to sustaining lost weight [11-13]. However, in this study, there were no significant differences in the items of physical activity including setting objectives, stress, obstacle and support. One possible reason for this inconsistent result is that because we asked the participants regarding increasing physical activity; the participants who had already increased physical activity during the weight loss program and kept it during the follow-up period might not answer yes to the questions. Considering that SWM maintained significantly higher walking step counts than the USWM at the end of the followup after adjusting for age, sex, and the baseline values, keeping higher physical activity may, related to weight maintenance. However, more studies are needed to examine the role of physical activity in weight maintenance.

In this study, we defined successful weight maintainers (SWMs) as those who maintained a weight loss of $5 \%$ or more of their initial weight at the one-year follow-up assessment, and the others were defined as unsuccessful weight maintainers (USWMs). USWMs included the participants who had not succeeded in achieving a 5\% weight loss (we named this group USWM1) and those who initially reached a $5 \%$ weight loss but could not maintain it (we named this 
group USWM2). We therefore analyzed these two groups (data not shown); at the end of the program, USWM2 walked significantly more than USWM1. The results of the increased number of steps walked per day in USWM2 were consistent with the results of SWM. In addition, more USWM2 participants felt less stress and difficulty in carrying out their dietary objectives than the participants in USWM1. During the follow-up period, significantly fewer participants in USWM2 set dietary objectives than the participants in USWM1. This might be one of the causes of decreased motivation and weight gain.

In this study, we examined which behaviors were important for successful weight maintenance. However, there are limitations in this study; as already discussed, in the followup survey, because we assessed only whether or not the participants increased their physical activity, there is a possibility that this affected our results. Another limitation is that the questionnaire surveys were conducted at the end of the program/follow-up. Thus, the participants already knew the amount of weight loss and this might affect the participants' answer to the questionnaires. However, in this study, we identified the difference between successful weight maintainers and unsuccessful weight maintainers and some of these results were consistent with the results of previous studies. Because there have still been only a few studies focused on this topic, more studies are needed to accumulate evidence.

\section{Conclusion}

The results of this study suggested that in addition to a substantial initial weight loss due to an increased amount of physical activity, having a higher self-efficacy for weight control behaviors, as well as keeping records of the activities and regularly weighing themselves may be important factors for successful weight maintenance. These results may be useful to provide advice for individuals who have completed weight loss programs.

\section{Acknowledgments}

The authors thank Ms. Ide, a section manager of the Saku General Hospital Human Dock Center, Ms Hashimoto, chief nurse of the Saku General Hospital Human Dock Center, and many medical staff and colleagues for supporting this program in Saku General Hospital. This study was partly supported by a Research-in-Aid Grant for Cardiovascular Diseases from the Ministry of Health, Labor and Welfare. The authors are with SCOP group.

\section{References}

[1] X. Formiguera and A. Cantón, "Obesity: epidemiology and clinical aspects," Best Practice and Research: Clinical Gastroenterology, vol. 18, no. 6, pp. 1125-1146, 2004.

[2] Ministry of Health, Labour and Welfare, "The results of the national nutrition survey in Japan," 2006, http://www .mhlw.go.jp/stf/houdou/2r9852000000xtwq.html.

[3] K. Ishikawa-Takata, T. Ohta, K. Moritaki, T. Gotou, and S. Inoue, "Obesity, weight change and risks for hypertension, diabetes and hypercholesterolemia in Japanese men," European Journal of Clinical Nutrition, vol. 56, no. 7, pp. 601-607, 2002.

[4] K. Nakayama, Y. Koyohara, I. Kato, H. Iwamoto, K. Ueda, and M. Fujishima, "Effect of body mass index on morbidity and mortality in a general Japanese population-the Hisayama study," Japanese Journal of Geriatrics, vol. 34, no. 11, pp. 935941, 1997 (Japanese).

[5] D. J. Goldstein, "Beneficial health effects of modest weight loss," International Journal of Obesity, vol. 16, no. 6, pp. 397$415,1992$.

[6] G. Blackburn, "Effect of degree of weight loss on health benefits," Obesity Research, vol. 3, pp. 211s-216s, 1995.

[7] R. W. Jeffery, A. Drewnowski, L. H. Epstein et al., "Long-term maintenance of weight loss: current status," Health Psychology, vol. 19, no. 1, pp. 5s-16s, 2000.

[8] S. W. Fletcher, J. E. Buring, S. N. Goodman et al., "Methods for voluntary weight loss and control," Annals of Internal Medicine, vol. 119, no. 7, part 2, pp. 764-770, 1993.

[9] J. W. Anderson, E. C. Konz, R. C. Frederich, and C. L. Wood, "Long-term weight-loss maintenance: a meta-analysis of US studies," American Journal of Clinical Nutrition, vol. 74, no. 5, pp. 579-584, 2001.

[10] J. S. Stern, J. Hirsch, S. N. Blair et al., "Weighing the options: criteria for evaluating weight-management programs. The Committee to Develop Criteria for Evaluating the Outcomes of Approaches to Prevent and Treat Obesity," Obesity Research, vol. 3, no. 6, pp. 591-604, 1995.

[11] P. J. Teixeira, S. B. Going, L. B. Houtkooper et al., "Pretreatment predictors of attrition and successful weight management in women," International Journal of Obesity, vol. 28, no. 9, pp. 1124-1133, 2004.

[12] R. R. Wing and J. O. Hill, "Successful weight loss maintenance," Annual Review of Nutrition, vol. 21, pp. 323-341, 2001.

[13] C. A. Befort, E. E. Stewart, B. K. Smith, C. A. Gibson, D. K. Sullivan, and J. E. Donnelly, "Weight maintenance, behaviors and barriers among previous participants of a university-based weight control program," International Journal of Obesity, vol. 32, no. 3, pp. 519-526, 2008.

[14] S. Sasaki, R. Yanagibori, and K. Amano, "Self-administered diet history questionnaire developed for health education: a relative validation of the test-version by comparison with 3day diet record in women," Journal of Epidemiology, vol. 8, no. 4, pp. 203-215, 1998.

[15] S. Sasaki, R. Yanagibori, and K. Amano, "Validity of a self-administered diet history questionnaire for assessment of sodium and potassium: comparison with single 24-hour urinary excretion," Japanese Circulation Journal, vol. 62, no. 6, pp. 431-435, 1998.

[16] S. Sasaki, F. Ushio, K. Amano et al., "Serum biomarker-based validation of a self-administered diet history questionnaire for Japanese subjects," Journal of Nutritional Science and Vitaminology, vol. 46, no. 6, pp. 285-296, 2000.

[17] K. Ookuma and M. Ookuma, "Behavioral modification therapy," Nippon Rinsho, vol. 61, pp. 631-639, 2003 (Japanese).

[18] M. Miyachi, Y. Ohmori, K. Yamamoto et al., "The use of a uniaxial accelerometer to assess physical-activity-related energy expenditure in obese men and women: Saku Control Obesity Program (SCOP)," Journal of Anti-Aging Medicine, vol. 5, pp. 1-5, 2008.

[19] S. M. Byrne, "Psychological aspects of weight maintenance and relapse in obesity," Journal of Psychosomatic Research, vol. 53, no. 5, pp. 1029-1036, 2002. 


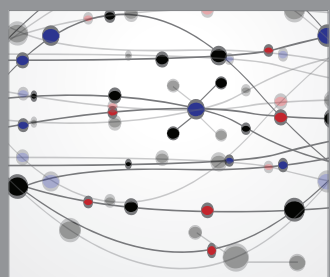

The Scientific World Journal
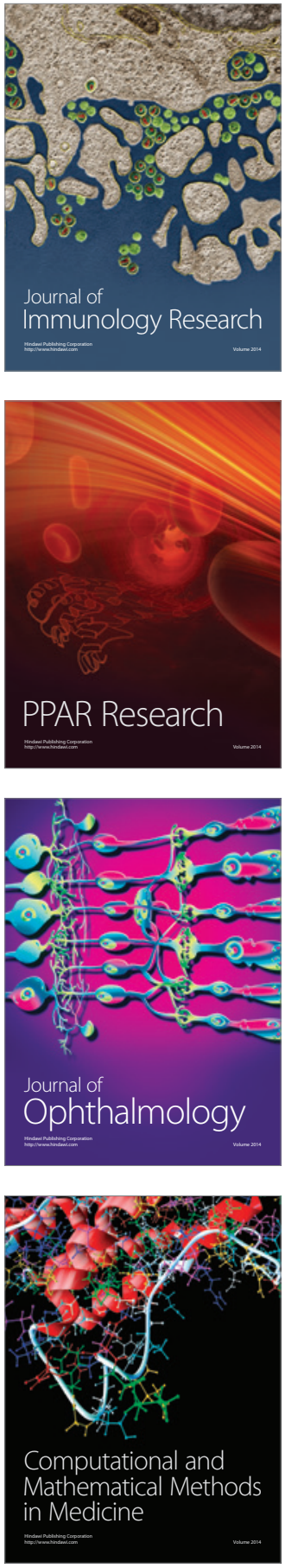

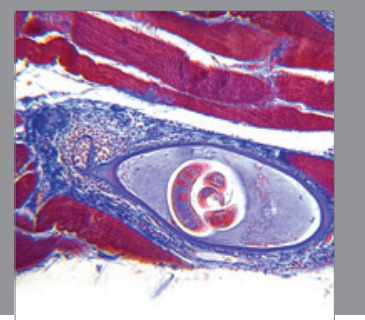

Gastroenterology

Research and Practice
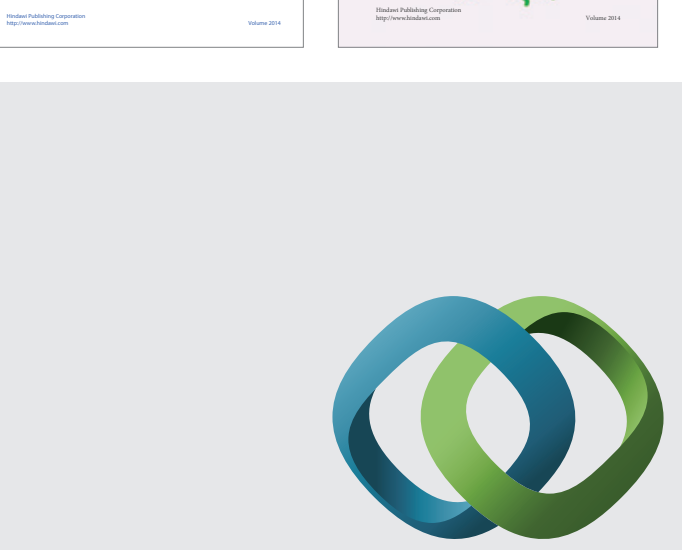

\section{Hindawi}

Submit your manuscripts at

http://www.hindawi.com
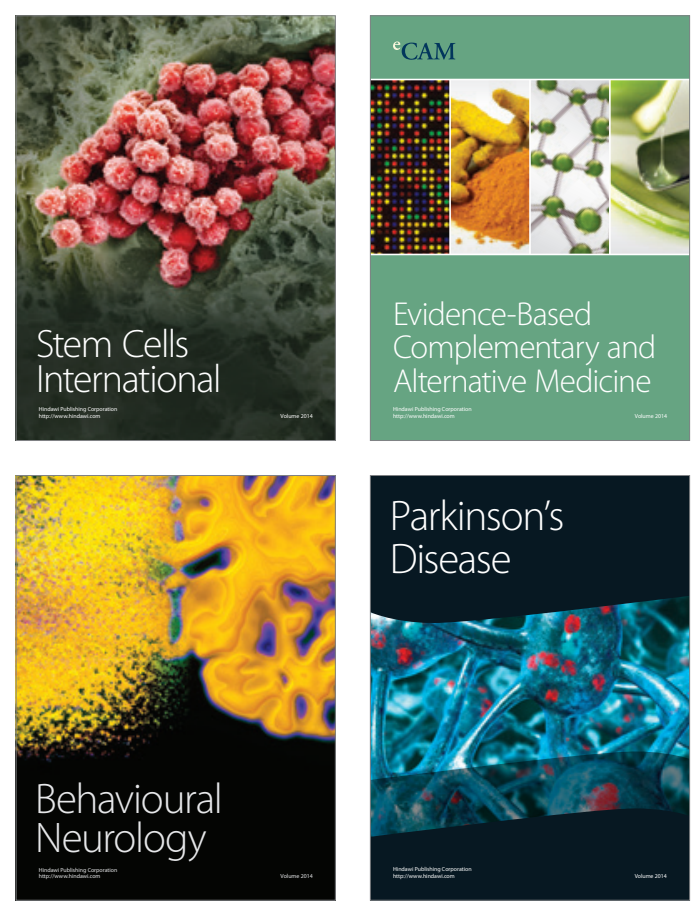

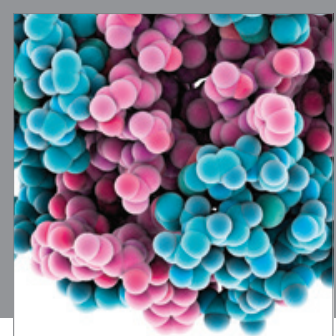

Journal of
Diabetes Research

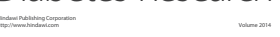

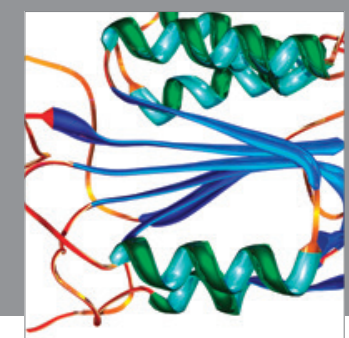

Disease Markers
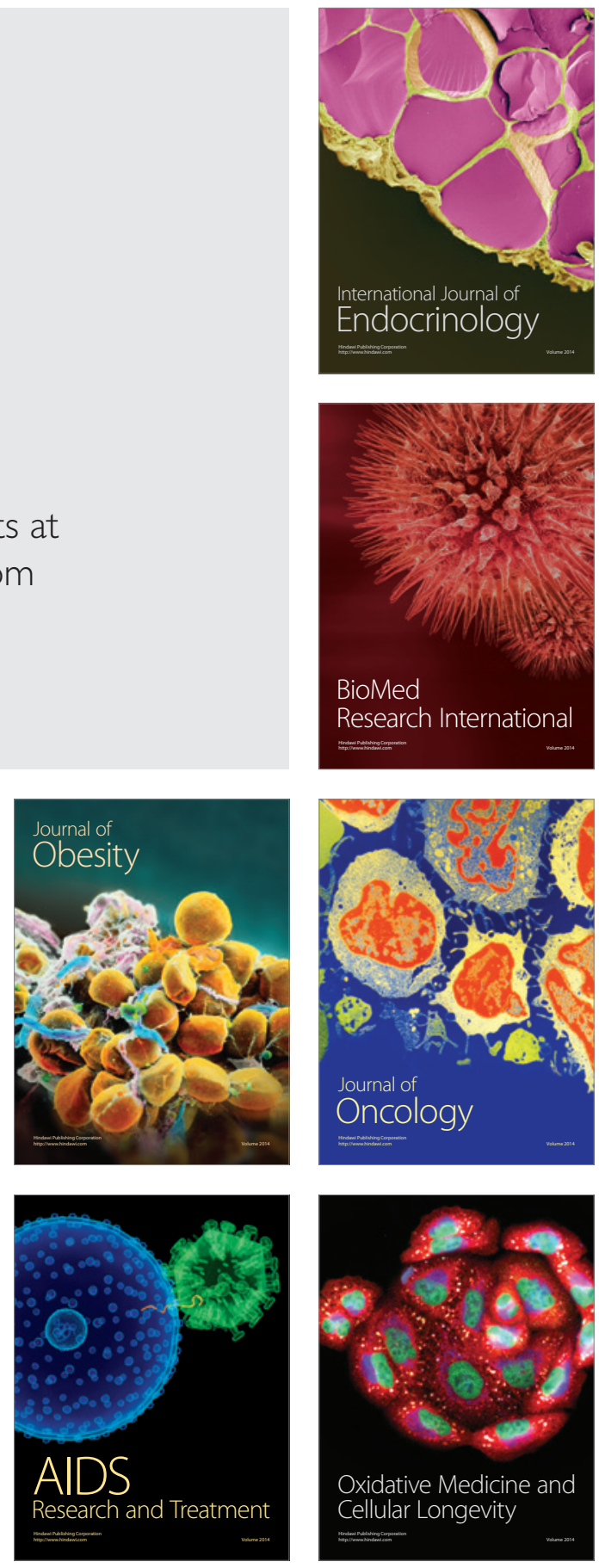